\title{
Validasi Modul: Terapi Kelompok Suportif Ekspresif untuk Menurunkan Depresi pada Wanita yang Mengalami Infertilitas Primer
}

\author{
Khabibah Solikhah ${ }^{1}$ E Noor Rachman Hadjam ${ }^{2}$ \\ Fakultas Psikologi Universitas Gadjah Mada
}

\begin{abstract}
The aim of this study was to examine the validity of Supportive Expressive Group Therapy modules to reduce depression in infertility women. Twelve people participated in this research. Validation encompassed two processes, which were content validity and empirical validity tests. The results of validity content through professional judgments showed that the coefficient of validity Aiken's V moved from 0.58 to 0.92 with reliability coefficient of 0.972 which indicated that the module had good content validity. While empirical validity testing was done using quasi experiment method. Analysis method used nonparametric Mann Whitney U-test. The result of the analysis showed that $Z$-score $=-2.756$ with $p=0.006(p<0.05)$. This suggested that there was a significant difference between the level of depression in the control group and the experimental group after receiving supportive expressive therapy.
\end{abstract}

Keywords: depression; infertility; module of supportive expressive group therapy

\begin{abstract}
Abstrak. Penelitian ini bertujuan untuk menguji validitas modul Terapi Kelompok Suportif Ekspresif (TKSE) yang disusun oleh peneliti dalam menurunkan depresi pada wanita yang mengalami infertilitas primer. Subjek pada penelitian ini berjumlah 12 orang. Validasi meliputi dua proses, yaitu uji validitas konten dan validitas empiris Berdasarkan hasil pengujian validitas isi melalui professional judgement, didapatkan koefisien validitas Aiken's $V$ bergerak dari 0,58 sampai 0,92 dengan koefisien reliabilitas sebesar 0,972 . Hal ini menunjukkan bahwa modul yang disusun memiliki validitas isi baik. Sedangkan pengujian validitas empirik dilakukan dengan metode eksperimen kuasi. Analisis statistik menggunakan nonparametrik Mann Whitney U-test menunjukkan besarnya $Z$-score $=-2,756$ dengan $p=0,006(p<0,05)$. Hal tersebut menunjukkan modul TKSE yang disusun peneliti mampu menurunkan depresi pada wanita yang mengalami infertilitas primer.
\end{abstract}

Kata kunci : depresi; infertilitas; modul terapi kelompok suportif ekspresif

Pernikahan merupakan suatu peristiwa yang dianggap sakral bagi setiap orang. Whalstrom, William, dan Sawyer (2006) menyatakan bahwa melalui sebuah perni-

${ }^{1}$ Korespondensi dapat dilakukan melalui: khabibah.solikhah@gmail.com

${ }^{2}$ Atau melalui nrochman@ugm.ac.id kahan, pasangan suami istri memiliki harapan untuk bisa saling mencintai, harapan untuk bahagia dan keinginan untuk bisa menjadi orang tua. Kehadiran anak dalam keluarga akan meningkatkan kualitas hidup pasangan suami istri. Oleh karena itu, pasangan suami istri akan merasa "kurang lengkap" ketika belum 
juga dikaruniai anak meskipun telah membangun rumah tangga bertahuntahun. Dunia medis menyebut kondisi ini dengan istilah, infertilitas.

Infertilitas merupakan kegagalan pasangan suami istri untuk mendapatkan kehamilan, sekurang-kurangnya dalam 12 bulan berhubungan seksual secara teratur tanpa alat kontrasepsi. Infertilitas dibagi dalam dua kategori, yakni infertilitas primer dan infertilitas sekunder. Infertilitas primer terjadi apabila wanita sama sekali belum pernah mencapai pembuahan atau kehamilan. Sedangkan infertilitas sekunder adalah ketidakmampuan wanita untuk mempertahankan kehamilannya. Selain itu dikenal juga infertilitas idiopatik yang mengacu pada kondisi dimana pasangan suami istri telah menjalani pemeriksaan standar meliputi tes ovulasi, patensi tuba, dan analisis semen dengan hasil normal (Himpunan Endokrinologi Reproduksi dan Fertilitas Indonesia [HIFERI], 2013).

Pihak wanita paling sering disudutkan dan disalahkan bila dalam suatu pernikahan belum juga dikaruniai anak. Hal tersebut disebabkan adanya anggapan bahwa mengandung, melahirkan, mengasuh dan mendidik anak adalah tanggung jawab yang harus dipenuhi oleh seorang wanita untuk bisa mengangkat harkat dan martabatnya (Dariyo, 2004). Pernyataan ini sejalan dengan hasil penelitian yang dilakukan oleh Demartoto (2008) terhadap masyarakat Jawa yang mengalami infertilitas di Surakarta. Pada masyarakat patriakal Jawa, laki-laki diidentikkan dengan individu yang kuat, sedangkan anak dianggap sebagai sumber kejantanan, kekuatan, serta kapasitas seksual laki-laki. Persepsi tersebut membuat laki-laki merasa rendah diri ketika pernikahannya tidak juga dikaruniai anak, sehingga kesalahan dilimpahkan pada pasangannya.

Infertilitas memang bukan sebuah kondisi penyakit yang mengancam kehidupan, tapi dampak psikologisnya sangat mempengaruhi individu, bahkan sebanding dengan dampak psikologis dari penyakit kronik (Anggraeni, 2009). Wanita, sebagai pihak yang selalu disalahkan, rentan mengalami berbagai tekanan psikologis yang dapat berkembang menjadi depresi. Selain itu, wanita yang mengalami infertilitas juga cenderung merasa kurang feminim, harga diri rendah, lebih sensitif, mengalami stres psikologi, dsyphoria, serta penurunan fungsi seksual (Burt \& Hendrick, 2005). Lebih lanjut, penelitian yang dilakukan oleh Karaca \& Unsal (2015) menemukan terdapat sembilan permasalahan psikososial yang dialami oleh wanita infertil, yaitu makna menjadi wanita infertil, konsep diri negatif, adanya tekanan sosial, adanya dukungan sosial, simtom psikis, menarik diri dari pergaulan, coping spiritual, menyusun kembali tujuan hidup, dan permasalahan terkait pengobatan atau program hamil.

Depresi merupakan suatu kondisi yang ditandai dengan munculnya perasaan tidak puas, menurunnya aktivitas, serta perasaan pesimis menghadapi masa depan (Chaplin, 2011). Pedoman Penggolongan dan Diagnosa Gangguan Jiwa (Maslim, 2003), menyebutkan gejala utama depresi yaitu afek depresif, kehilangan minat dan kegembiraan, serta berkurangnya energi menuju meningkatnya keadaan mudah lelah. Selain itu ada juga gejala lain yang menyertai antara lain berkurangnya konsentrasi dan perhatian, harga diri menurun, gagasan tentang rasa bersalah, pesimis menghadapi masa depan, gagasan bunuh diri, gangguan tidur, serta 
berkurangnya nafsu makan. Banyak faktor yang dapat menjadi penyebab terjadinya depresi, antara lain faktor biologis, psikologi dan sosial budaya (Mufson, Bufka, \& Wright, 2016). Kondisi depresi yang dialami oleh wanita infertil tidak bisa diabaikan, melainkan harus ditangani dengan baik. Wanita yang mengalami infertilitas tidak hanya perlu penanganan medis, tapi juga pendampingan secara psikologis. Kondisi psikologis yang tidak seimbang berpotensi memperburuk masalah fisik (gangguan tuba, gangguan uterus, infeksi saluran urogenital dll). Kondisi psikologis tidak seimbang menyebabkan neurotransmitter terganggu akibatnya hormon kesuburan ikut terganggu hingga akhirnya memperburuk kondisi fisik.

Sehubungan dengan hal tersebut, perlu adaya intervensi psikologis bagi wanita yang mengalami infertilitas. Penelitian yang dilakukan Watson dan Kissane (2011) terhadap pasien kanker, menemukan terdapat terapi kelompok yang dapat digunakan untuk menurunkan depresi, yakni supportive expressive group therapy (terapi kelompok suportif ekspresif). Terapi kelompok suportif ekspresif (TKSE) merupakan terapi yang dimaknai dengan keterbukaan dalam memaknai emosi, pikiran dan perilaku (Fobair, Koopman, DiMiceli, O'Hanlan, Butler \& Classen, 2002). TKSE merupakan bagian dari brief psychodinamic dan merupakan kombinasi dari terapi suportif, existensial, cognitive behavioral, dan interpersonal (Hersen \& Sledge, 2002; Kissane, 2004; SAMHSA, 2012). Ciri khas psikodinamik dari TKSE terletak pada adanya proses katarsis, penekanan pada tumbuhnya transference, adanya proses klarifikasi, konfrontasi, dan interpretasi dengan teknik CCRT.
Terapi kelompok suportif ekspresif memiliki dua elemen utama, yakni supportive technique dan expressive technique (Luborsky, 1984). TKSE merupakan salah satu terapi yang dianggap mampu mengatasi gangguan psikologis, antara lain gangguan kecemasan, ketergantungan obat, penyalahgunaan obat, serta depresi. Tujuan dari TKSE adalah membantu partisipan untuk mengerti dan memahami pola hubungan yang menyebabkan konflik dalam konteks hubungan yang mendukung melalui adanya support system dalam kelompok (Connoly, Cristoph, Shappell, Barber, \& Luborsky, 1998). Tujuan ini akan tercapai dengan teknik CCRT (Core Conflict Relation Theme). CCRT adalah metode interpretasi untuk mengetahui pola hubungan klien dengan orang lain, termasuk dengan terapis. Pola konflik ini akan didapatkan terapis dari pengulangan tema di seluruh narasi dalam tiap sesi terapi. Teknik interpretasi CCRT merupakan metode yang mudah dilakuka, valid, dan dapat diterapkan pada jenis terapi singkat (Hersen \& Sledge, 2002; Connolly, CritsChristoph, Barber, \& Luborsky, 2000).

CCRT dilakukan terapis untuk membantu partisipan menemukan inti permasalahan (core conflict) yang dialami selama ini, melalui identifikasi masalah yang selama ini dimiliki oleh partisipan. Luborsky (1984) mengungkapkan bahwa CCRT memiliki tiga elemen yakni Wish (apa yang diingkan partisipan dari orang lain), Respons of others (reaksi lingkungan terhadap partisipan), dan respons of self (bagaimana respon partisipan terhadap reaksi lingkungan). TKSE untuk depresi didasarkan pada keyakinan bahwa gejala depresi akan mereda saat partisipan mulai memahami pola hubungan maladaptif mereka dan mulai menerapkan respons 
interpersonal yang lebih adaptif (Luborsky, 1984).

Sejauh ini, penelitian yang pernah dilakukan menunjukkan bahwa TKSE mampu menurunkan tingkat depresi pada penderita kanker payudara (Yunitri, 2012), mampu meningkatkan harapan dan kualitas hidup pasien multiple sclerosis (Abolghasemi et al., 2016), mampu mengurangi gejala depresi pada pasien HIV (Heckman et al., 2013; Cahyamita, 2015), menurunkan stres pada pasien metastase kanker payudara (O'Brien Harris, King, \& O'Brien, 2008), mampu menurunkan kesedihan dan perasaan kesepian yang dialami oleh korban genosida di Rwanda (Gishoma, Brackelaire, Munyandamutsa, Mujaweyazu, Mohand \& Kayiteshonga, 2014), serta mampu menurunkan konsumsi obatobatan terlarang pada cocaine dependence (Crits-Christoph et al., 2008). Namun, sejauh ini belum ada penelitian mengenai dampak TKSE pada wanita yang mengalami infertilitas, sehingga peneliti tertarik untuk menyusun modul terapi kelompok suportif ekspresif untuk wanita menikah yang mengalami infertilitas primer. Penelitan ini bertujuan untuk melakukan validasi terhadap modul terapi kelompok suportif ekspresif terhadap penurunan depresi pada wanita yang mengalami infertilitas. Hipotesis dalam penelitian ini ada dua, pertama modul TKSE yang disusun peneliti memiliki validitas isi yang baik. Kedua, modul TKSE yang disusun peneliti mampu menurunkan depresi pada wanita yang mengalami infertilitas primer.

\section{Metode}

Penelitian ini bertujuan untuk melakukan validasi terhadap modul Terapi Kelompok Suportif Ekspresif yang disusun oleh peneliti. Penyusunan modul melalui tahapan yang diungkapkan oleh Russell (1974) yang meliputi identifikasi tujuan pembuatan modul, penyusunan alat ukur, penetapan target perilaku, ujicoba modul, dan evaluasi. Modul disusun dengan berpedoman pada modul Terapi Kelompok Suportif Ekspresif yang disusun oleh Maldonado (1996) serta berdasarkan hasil penelitian Karaca \& Unsal (2015) tentang permasalahan psikososial yang dialami oleh wanita infertil yakni konsep diri negatif, makna menjadi wanita infertil, adanya tekanan sosial, kurangnya dukungan sosial, menyusun tujuan hidup kembali, menarik diri dari pergaulan, coping spiritual, menyusun kembali tujuan hidup, dan permasalahan terkait pengobatan atau program hamil. Setelah modul selesai disusun, selanjutnya dilakukan pengujian validitas.

Pengujian dilakukan terhadap validitas isi modul, melalui professional judgment, dan terhadap validitas empirik, dengan kuasi eksperimen. Pengujian validitas isi dilakukan dengan meminta penilaian dari tiga orang rater yang merupakan psikolog praktisi dalam bidangnya masing-masing. Hasil penilaian kemudian dianalisis dengan Aiken's V untuk mendapatkan koefisien validitas modul.

Pengujian validitas empirik dilakukan melalui eksperimen semu dengan rancangan Untreated control group design with pretest and posttest design. Partisipan dalam penelitian berjumlah 12 orang yang terbagi dalam kelompok eksperimen (6 orang) dan kelompok kontrol (6 orang). Pengukuran depresi pada partisipan penelitian menggunakan PHQ-9. Analisis data dalam pengujian empirik menggunakan analisis 
Tabel 1.

Rekapitulasi Data Demografis Partisipan

\begin{tabular}{|c|c|c|c|c|}
\hline Karakteristik & & $\begin{array}{l}\text { Total } \\
\text { n(\%) }\end{array}$ & $\begin{array}{c}\text { Kelompok } \\
\text { eksperimen } \\
n=6(\%)\end{array}$ & $\begin{array}{c}\text { Kelompok } \\
\text { kontrol } \\
\mathrm{n}=6(\%)\end{array}$ \\
\hline \multirow[t]{3}{*}{ Usia } & $26-30$ & $7(58,3 \%)$ & $2(33,33 \%)$ & $3(50 \%)$ \\
\hline & $31-35$ & $3(25 \%)$ & $2(33,33 \%)$ & $1(16,67 \%)$ \\
\hline & $36-40$ & $2(16,67 \%)$ & $2(33,33 \%)$ & $0(0 \%)$ \\
\hline \multirow[t]{5}{*}{ Pekerjaan } & IRT & $3(25 \%)$ & $1(16,67 \%)$ & $2(33,33 \%)$ \\
\hline & Swasta & $2(16,67 \%)$ & $1(16,67 \%)$ & $1(16,67 \%)$ \\
\hline & Guru & $5(41,67 \%)$ & $3(50 \%)$ & $2(33,33 \%)$ \\
\hline & PNS & $1(8,33 \%)$ & $0(0 \%)$ & $1(16,67 \%)$ \\
\hline & Wiraswasta & $1(8,33 \%)$ & $1(16,67 \%)$ & $0(0 \%)$ \\
\hline \multirow[t]{2}{*}{ Pendidikan } & SMA & $1(8,33 \%)$ & $0(0 \%)$ & $1(16,67 \%)$ \\
\hline & Sarjana & $11(91,67 \%)$ & $6(100 \%)$ & $5(83,33 \%)$ \\
\hline \multirow[t]{2}{*}{ Usia pernikahan } & 3-5 tahun & $7(58,33 \%)$ & $3(50 \%)$ & $4(66,67 \%)$ \\
\hline & 6-9 tahun & $5(41,67 \%)$ & $3(50 \%)$ & $3(50 \%)$ \\
\hline
\end{tabular}

nonparametrik. Teknik analisis nonparametrik yang digunakan yaitu Mann-Whitney $U$ test. Adapun kriketria inklusi partisipan yaitu wanita yang mengalami infertilitas primer (wanita menikah yang sekurang-kurangnya selama 12 bulan berhubungan seksual tanpa kontrasepsi, tapi belum pernah mengalami kehamilan), berusia 25 tahun 40 tahun, usia pernikahan minimal 3 tahun, memiliki tingkat depresi ringan atau depresi sedang yang diukur dengan PHQ9, pendidikan minimal SMA, mampu membaca dan berkomunikasi dengan baik (tidak mengalami gangguan pendengaran atau bicara), terapis memegang peranan penting dalam proses terapi. Oleh karena itu, terdapat beberapa kriteria yang harus dipenuhi oleh terapis yang akan memandu terapi kelompok suportif ekspresif. Adapun kriteria terapis yaitu memiliki Surat Izin Praktik Psikolog (SIPP) yang masih berlaku, memiliki pemahaman mengenai brief therapy, khususnya dengan pendekatan psikodinamik, sudah menikah dan memiliki anak, emiliki pengalaman dalam memberikan dukungan psikososial bagi wanita menikah, memiliki kemampuan dan pengalaman dalam memandu terapi kelompok, dan memiliki pemahaman mengenai infertilitas.

\section{Hasil}

Berdasarkan perhitungan dengan Aiken's $\mathrm{V}$, hasil koefisien validitas bergerak dari 0,58 sampai 0,92 , dengan rerata 0,84 dan koefisien reliabilitas sebesar 0,972. Azwar (2014) menyatakan bahwa nilai koefisien validitas yang berkisar 0,50 sudah dapat dianggap memuaskan. Hal tersebut menunjukkan bahwa modul TKSE yang disusun oleh peneliti sudah dianggap memuaskan.

Proses pengujian validitas empirik dilakukan melalui desain Untreated control group design with pretest and posttest design. Adapun partisipan penelitian sejumlah 12 orang, dengan data demografis pada Tabel 1. 
Berdasarkan hasil pengukuran (baseline dan pretest) dan setelah intervensi dengan PHQ-9 sebelum intervensi (postest) didapatkan hasil pada tabel 2.

Tabel 2.

Statistik Deskriptif Skor PHQ-9

\begin{tabular}{lcccccc}
\hline & \multicolumn{2}{c}{ Baseline } & \multicolumn{2}{c}{ Pretes } & \multicolumn{2}{c}{ Postes } \\
& Eksperimen & Kontrol & Eksperimen & Kontrol & Eksperimen & Kontrol \\
\hline Minimum & 7 & 7 & 8 & 9 & 2 & 9 \\
Maximum & 10 & 12 & 11 & 13 & 8 & 15 \\
Mean & 7,67 & 8,67 & 9,33 & 10,33 & 4,67 & 10,83 \\
Std. & 1,211 & 1,966 & 1,211 & 1,751 & 2,066 & 2,137 \\
Deviation & & & & & & \\
\hline
\end{tabular}

Tabel 3.

Hasil Uji Mann-Whitney U Gain Score Pretes dan Postes Kelompok Eksperimen dan Kelompok Kontrol

\begin{tabular}{ll}
\hline Test Statistics & \\
\hline & GainScore \\
\hline Mann-Whitney U & 1,000 \\
\hline Wilcoxon W & 22,000 \\
\hline$Z$ & $-2,756$ \\
\hline Asymp. Sig. (2-tailed) &, 006 \\
\hline Exact Sig. [2*(1-tailed Sig.)] &, $004^{\mathrm{b}}$ \\
\hline a. Grouping Variable: Kelompok & \\
\hline b. Not corrected for ties. & \\
\hline
\end{tabular}

Tabel 2 menunjukkan bahwa ratarata (mean) skor PHQ-9 postes pada kelompok eksperimen mengalami penurunan dibandingkan rata-rata skor pada pengukuran baseline maupun pretes. Yakni dari rata-rata baseline 7,67 kemudian rata-rata meningkat pada saat pretes menjadi 9,33 dan pada saat postes menurun menjadi 4,67. Sedangkan ratarata postes pada kelompok kontrol justru mengalami peningkatan dibanding ratarata pada saat baseline maupun pretes, yakni dari 8,67 menjadi 10,33 dan semakin meningkat menjadi 10,83. Hal ini menunjukkan bahwa setelah mendapatkan TKSE, tingkat depresi kelompok eksperimen mengalami penu- runan, sedangkan pada kelompok kontrol justru mengalami peningkatan.

Perubahan rata-rata skor depresi (diukur dengan PHQ-9) pada kelompok eksperimen dan kelompok kontrol di tunjukkan pada gambar 4. Adapun hasil uji Mann Whitney U-test dapat dilihat pada tabel 4. Adapun hasil uji Mann Whitney $U$ test dapat dilihat pada tabel 3.

$$
\text { Hasil yang didapatkan }
$$
menunjukkan besarnya Z-score $=-2,756$ dengan $p=0,006$. Karena nilai $p<0,05$, maka dapat dijelaskan bahwa ada perbedaan yang signifikan tingkat depresi pada kelompok kontrol dengan kelompok eksperimen setelah mendapatkan terapi suportif ekspresif. 
Tabel 4.

Hasil Uji Wilcoxon pada Pengukuran Pretes dan Postes Kelompok

Eksperimen

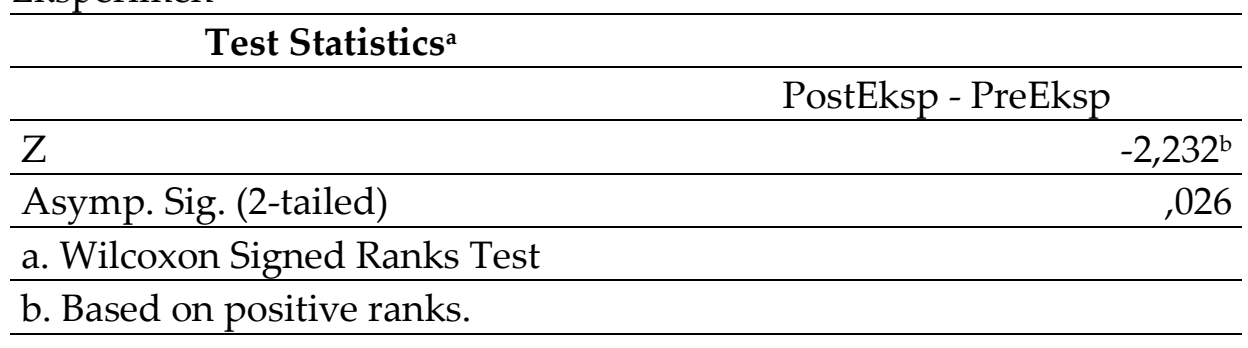

Selanjutnya, peneliti juga melakukan analisis terhadap nilai pretes kelompok ekperimen dengan nilai postes kelompok eksperimen dengan menggunakan signrank Wilcoxon. Analisis ini bertujuan untuk mengetahui apakah pemberian terapi kelompok suportif ekspresif dapat menurunkan depresi pada wanita menikah dengan gangguan infertilitas. Adapun hasil analisis ditunjukkan pada Tabel 4.

Hasil yang didapatkan yakni nilai signifikansi sebesar 0,026 $(\mathrm{p}<0,05)$. Hal tersebut menunjukkan bahwa terdapat perubahan signifikan antara skor pretes dengan skor postes kelompok ekperimen. Artinya terjadi perubahan yang signifikan pada skor depresi pada partisipan kelompok eksperimen antara sebelum dengan sesudah diberikan terapi kelompok suportif ekspresif. Berdasarkan analisis uji hipotesis dapat disimpulkan bahwa modul terapi kelompok suportif ekspresif yang disusun oleh peneliti dapat menurunkan tingkat depresi pada wanita menikah yang mengalami gangguan infertilitas.

\section{Diskusi}

Tujuan dari penelitian ini adalah untuk melakukan validasi terhadap modul Terapi Kelompok Suportif Ekspresif (TKSE) untuk menurunkan depresi pada wanita yang mengalami infertilitas primer. Pengujian dilakukan terhadap validasi isi modul dan validasi empirik. Berdasar pengujian validasi isi dengan proffessional judgment didapatkan hasil koefisien validitas bergerak dari 0,58 sampai 0,92 dengan koefisien reliabilitas sebesar 0,972. Hasil ini menunjukkan bahwa modul TKSE yang disusun peneliti memiliki validasi isi yang memuaskan.

Selanjutnya pengujian validitas empirik dilakukan dengan menggunakan analisis nonparametrik. Berdasarkan hasil uji hipotesis dengan Mann-Whitney U-test terbukti bahwa terdapat perbedaan yang signifikan antara tingkat depresi kelompok kontrol dengan kelompok eksperimen setelah diberikan TKSE. Hal ini dapat dilihat dari z hitung sebesar 2,756 dengan nilai probabilitas $(p)$ sebesar $0,006(0,006<0,05)$. Partisipan kelompok eksperimen yang mendapatkan perlakuan berupa terapi kelompok suportif ekspresif cenderung mengalami penurunan skor depresi, sedangkan partisipan kelompok kontrol menunjukkan skor depresi yang tetap, bahkan tiga partisipan mengalami kenaikan skor depresi. Selain itu, hasil uji analisis dengan Wilcoxon menunjukkan bahwa terdapat perbedaan skor depresi yang signifikan antara sebelum diberikan terapi dengan sesudah diberikan terapi. Hal ini ditunjukkan dengan nilai signifikansi sebesar 0,026 $(p<0,05)$ dan $z$ 
hitung -2,232. Berdasarkan uji hipotesis tersebut dapat disimpulkan bahwa modul TKSE yang disusun oleh peneliti mampu menurunkan tingkat depresi pada wanita menikah yang mengalami gangguan infertilitas. Hasil penelitian ini sesuai dengan hasil penelitian yang dilakukan oleh Cahyamita (2015) dan Heckman et al. (2013) yang menemukan bahwa TKSE dapat menurunkan depresi pada penderita HIV/AIDS, serta hasil penelitian yang dilakukan oleh Yunitri (2012) yang menemukan bahwa TKSE mampu menurunkan depresi pada penderita kanker.

Salah satu tujuan individu menikah adalah untuk mendapatkan anak dan melestarikan keturunan. Anak dianggap sebagai simbol kebahagiaan dalam rumah tangga. Oleh karena itu, ketika dalam rumah tangga tidak juga dikarunia anak, kondisi tersebut akan menjadi stresor bagi pasangan suami istri. Kondisi yang sama juga dialami oleh seluruh partisipan penelitian. Bertahun-tahun membina rumah tangga tapi tidak juga dikaruniai anak. Tuntutan dari lingkungan mulai muncul.

Model psikodinamika terbaru lebih fokus pada perasaan individu terhadap self worth atau self esteem. Pada model self focussing , mempertimbangkan bagaimana mengalokasikan proses atensi individu setelah peristiwa kehilangan (kematian orang yang dicintai, kegagalan mendapatkan sesuatu, dan lain sebagainya). Menurut model ini individu yang mudah mengalami depresi adalah individu yang mengalami periode self examination (self focussing) yang intens setelah terjadinya kekecewaan yang besar. Individu menjadi terpaku pada pikiranpikiran mengenai objek atau sesuatu penting yang gagal diraih dan individu tersebut tidak dapat merelakan harapan yang hilang. Individu terus berusaha mendapatkan objek tersebut bagaimanapun caranya (Nevid, Rathus, Greene, 2005). Hal ini sesuai dengan kondisi seluruh partisipan, dimana mereka terpaku pada sesuatu yang dianggap penting tapi belum juga didapatkan, yakni anak. Di satu sisi, kondisi ini membuat partisipan mengerahkan seluruh usahanya untuk bisa mendapatkan apa yang diinginkan. Namun, disisi lain, kondisi ini menjadi stressor bagi partisipan. Terutama jika upaya yang mereka lakukan tidak kunjung membuahkan hasil.

Berdasarkan hasil wawancara diketahui bahwa seluruh partisipan mengalami permasalahan dengan organ reproduksinya. Kondisi ini kemudian memunculkan simptom rasa bersalah pada diri partisipan, karena meyakini bahwa belum hadirnya anak disebabkan oleh mereka. Perasaan tersebut diperkuat dengan adanya stigma masyarakat bahwa mengandung, melahirkan, mengasuh dan mendidik anak adalah tanggung jawab yang harus dipenuhi oleh seorang wanita untuk bisa mengangkat harkat dan martabatnya (Dariyo, 2004). Sehingga ketika dalam keluarga belum juga dikaruniai anak, maka yang patut disalahkan adalah pihak wanita. Teori psikodinamika meyakini bahwa depresi mewakili kemarahan yang diarahkan ke dalam diri sendiri (Nevid et al., 2005). Hal ini sesuai dengan yang dialami oleh seluruh partisipan, dimana mereka cenderung menyalahkan diri sendiri atas situasi yang dihadapi. Emosi marah bisa jadi merupakan manifestasi dari kesedihan yang dialami oleh partisipan.

Berdasarkan pengukuran dengan PHQ-9 dan wawancara, diketahui bahwa proses terapi kelompok suportif ekspresif mampu menurunkan simptom depresi 
pada seluruh partisipan. Pada sesi identifikasi diri, seluruh partisipan berupaya untuk mengidentifikasi perubahan yang dialami berkaitan dengan kondisi infertilitasnya, baik secara emosi, sosial, spiritual dan ekonomi. Selain itu, melalui sesi ini partisipan berusaha mengidentifikasi sumber kekuatan yang dimiliki, sehingga akan membantu partisipan mengubah pandangan negatif mengenai dirinya sendiri dan kondisi yang dialami. Beck \& Alford (2009) mengungkapkan bahwa individu yang mengalami depresi lebih memfokuskan pada penilaian diri negatif. Seperti halnya yang dialami oleh partisipan sebelum menjalani terapi, terfokus pada rasa bersalah dan tidak berharga karena belum bisa melahirkan anak. Partisipan yang berhasil mengidentifikasi perubahan yang dialami, akan mampu memetakan permasalahan dan merumuskan pemecahan yang tepat.

Selanjutnya pada sesi kedua, partisipan dipandu untuk mengidentifikasi dampak infertilitas terhadap hubungannya dan interaksinya dengan lingkungan. Tujuan sesi ini untuk membantu partisipan mengetahui pola hubungannya dengan lingkungan. Terapis, dengan teknik CCRT, mampu memandu partisipan merumuskan harapan (wish), respons from others, dan respon of self. Melalui teknik ini, partisipan lebih memahami apa yang diharapkan dari lingkungan dan respon apa yang harus ditunjukkan untuk mendapatkan reaksi lingkungan yang diinginkan, sehingga partisipan mampu menerapkan koping yng lebih adaptif. Luborsky (1984) menyatakan bahwa TKSE untuk depresi didasarkan pada keyakinan bahwa gejala depresi akan mereda saat partisipan mulai memahami pola hubungan maladaptif mereka dan mulai menerapkan respons interpersonal yang lebih adaptif.

Cara lain yang dilakukan oleh terapis adalah dengan menghadirkan kembali pengalaman-pengalaman traumatis yang memunculkan depresi. Proses menghadirkan kembali peristiwa menyakitkan dan memaknainya kembali terbukti mampu menurunkan simptom stres dan depresi. Salah satu pendekatan terapeutik pada individu yang mengalami stress dan depresi adalah dengan menghadirkan kembali peristiwa traumatik yang pernah dialami. Individu dipandu untuk menghadirkan kembali peristiwa tersebut sambil merasakan kembali emosi-emosi terkait. Termasuk di dalamnya adalah menemukan hikmah dari peristiwa tersebut dan memasukkan emosi-emosi positif di dalamnya sehingga individu mampu mengatasi rasa sakitnya dan melanjutkan hidup (Durand \& Barlow, 2006).

Pada sesi ketiga, partisipan dipandu untuk mengidentifikasi dampak dari promil yang dijalani. Tidak dapat dipungkiri bahwa serangkaian program hamil yang dijalani, memberikan dampak psikologis bagi pasangan infertil (HIFERI, 2013). Besarnya biaya yang dikeluarkan, serta ketidakpastian keberhasilan program menjadi stressor. Hal tersebut sangat dirasakan oleh seluruh partisipan, terutama Aster. Terapi kelompok SE membantu partisipan untuk mengidentifikasi problem solving yang dilakukan untuk menghadapi kondisi tersebut. Terjadi proses saling menguatkan antar partisipan. Hal ini akan membuat partisipan lebih siap menghadapi kondisi yang tidak diharapkan.

Pada sesi keempat memaknai hikmah, partisipan dipandu untuk memaknai kondisi infertilitasnya dengan 
lebih positif. Partisipan diajak untuk menilai kondisinya dari sudut pandang yang berbeda. Seluruh partisipan menyatakan bahwa salah satu hikmah dari kondisinya saat ini adalah semakin meningkatnya keterbukaan dan komunikasi dengan suami. Selanjutnya, pada sesi kelima, terapis memandu partisipan untuk menyusun kembali tujuan hidup yang lebih realistis, dengan mempertimbangkan kondisi infertilitas yang dialami. Partisipan diminta untuk menuliskan peran yang dijalani dalam hidup, perilaku yang ditunjukkan oleh masing-masing peran, kompetensi yang dimiliki saat ini, tujuan tertinggi yang ingin dicapai, kompetensi baru yang dibutuhkan, serta perilaku baru yang dibutuhkan untuk mencapai tujuan tersebut. Melalui sesi ini, partisipan merasa memiliki tujuan yang lebih konkrit untuk dicapai, sehingga partisipan merasa mampu menjalani hidup dengan lebih optimis.

Pada sesi kelima, terapis juga memadu partisipan untuk menghadirkan situasi yang tidak diinginkan, yakni jika sampai akhir hayat tidak dikaruniai anak. Seluruh partisipan mengakui bahwa mereka memiki kekhawatiran, jika sampai tidak memiliki anak. Garfield (dalam Karen, Hafe, Smith, \& Fradsen, 2002) mengungkapkan bahwa kekhawatiran merupakan suatu upaya untuk keluar dari ketakutan. Kekhawatiran tidak selalu bermakna negatif, melainkan bisa menjadi kekuatan yang mampu menggerakkan individu untuk mengambil langkah positif. Melalui sesi ini, partisipan diminta mengidentifikasi langkah apa yang akan dilakukan jika pada akhirnya Tuhan tidak menganugerahkan anak hingga akhir hayat. Tulip, Aster dan Edelweis mengungkapkan keinginannya untuk mengasuh anak yatim, Krisan mengungkapkan recananya untuk mendirikan rumah tahfidz bagi anak yatim. Sedangkan Azallea dan Lily mengungkapkan bahwa mereka akan fokus untuk bisa bermanfaat, lewat ilmu.

Krisan, di antara enam partisipan yang lain, menunjukkan penurunan skor depresi paling sedikit, yakni 1 poin. Berdasarkan analisa selama proses terapi, hal ini disebabkan karena Krisan terus melakukan penyangkalan (denial) terhadap simptom depresi yang muncul. Saat mulai muncul rasa sedih karena memikirkan kondisinya, Krisan akan langsung menyangkal rasa sedihnya dengan pikiran "aku tidak boleh sedih". Selain itu, Krisan juga menunjukkan mekanisme pertahananan diri disosiasi, dimana setiap kali ada pihak yang menyinggung mengenai kondisinya, Krisan memilih untuk memikirkan hal lain yang lebih menyenangkan. Freud mengungkapkan bahwa mekanisme pertahanan diri berfungsi untuk melindungi diri dari kecemasan. Namun, jika mekanisme dipergunakan secara berlebihan, dapat memunculkan gangguan psikologis (Halgin \& Whitbourne, 2010).

Partisipan dalam terapi kelompok masih cenderung didominasi oleh emosi negatif karena kondisinya, baik itu rasa marah, kecewa, sedih, maupun rasa bersalah. Oleh karena itu peneliti memberikan ketrampilan relaksasi di setiap akhir sesi. Penelitian yang dilakukan oleh Rachmawati (2015) menyimpulkan bahwa relaksasi dapat menurunkan ketegangan, menurunkan kecemasan, serta membangun emosi positif. Seluruh partisipan mengaku bahwa setiap kali selesai relaksasi, perasaan menjadi lebih tenang dan damai.

Lebih lanjut, salah satu faktor terapeutik dalam terapi yang mampu 
menurunkan depresi adalah adanya social support (dukungan sosial). Semakin tinggi dukungan sosial yang dimiliki maka akan menunjang proses kesembuhan gangguan depresi (Durand \& Barlow, 2006). Dukungan ini didapatkan melalui interaksi antar partisipan. Kohesivitas diperlukan untuk membangun interaksi dalam kelompok. Berdasarkan observasi, kohesivitas kelompok sangat tinggi. Kohesivitas ini yang membuat fungsi dalam kelompok menjadi semakin positif (Berg, Landreth, \& Fall, 2006).

Melalui proses terapi kelompok suportif ekspresif ini, seluruh partisipan dapat saling bertukar pengalaman dan informasi mengenai kondisi yang dialami. Selain itu partisipan juga memiliki ruang yang nyaman untuk bisa mengekspresikan emosinya, baik marah, sedih, kecewa, dan lain sebagainya. Mengekspresikan perasaan dalam kelompok merupakan mekanisme koping yang konstruktif untuk meningkatkan pengetahuan dan menciptakan hubungan sosial yang baik (Kissane, 2004). Selain itu, hal ini mampu menumbuhkan pengalaman positif pada seluruh partisipan, hingga partisipan menyadari bahwa apa yang dirasakan juga dialami oleh partisipan lain. Hal ini diperkuat dengan pernyataan Edelweis, Lily dan Aster yag mengungkapkan bahwa dukungan sosial yang diharapkan, berhasil didapat melalui proses terapi. Kondisi yang dialami seluruh partisipan ini sesuai dengan pernyataan Halgin dan Whitbourne (2010) yang menyatakan bahwa seringkali dukungan terbaik justru didapatkan dari individu yang mengalami permasalahan sama.

Di sisi lain, penelitian ini masih terdapat beberapa keterbatasan. Pertama, skrining partisipan masih terlalu longgar. Hal ini terbukti dengan adanya salah satu partisipan yang tidak sesuai dengan kriteria yang ditetapkan (infertilitas sekunder). Keterbatasan selanjutnya mengenai jumlah partisipan. Modul terapi yang disusun, penelitian akan lebih tepat jika menggunakan $N$-small group, yakni grup terapi dengan jumlah anggota sedikit. Jumlah partisipan tujuh orang, ternyata kurang efektif karena waktu yang dibutuhkan dalam proses terapi semakin panjang. Waktu yang kurang efektif menyebabkan tidak semua partisipan dapat terfasilitasi dengan baik.

Keterbatasan teknis berkaitan dengan tempat pelaksanaan terapi. Pelaksanaan terapi akan lebih baik jika menggunakan ruang yang kedap suara. Hal tersebut dilakukan dengan pertimbangan permasalahan yang diangkat adalah isu yang sensitif. Selain itu, selama proses terapi berlangsung akan lebih baik jika yang hadir dalam proses hanya pihak terkait, yakni partisipan, terapis dan peneliti.

\section{Kesimpulan}

Modul Terapi Kelompok Suportif Ekspresif (TKSE) yang disusun peneliti memiliki validitas isi yang baik serta terbukti mampu menurunkan depresi pada partisipan penelitian, yakni wanita menikah yang mengalami infertilitas primer. Hipotesis dalam penelitian ini diterima.

\section{Saran}

Peneliti selanjutnya disarankan melakukan skrining lebih ketat mengenai riwayat kehamilan ataupun keguguran yang dialami oleh partisipan untuk meningkatkan homogenitas dalam kelompok. Selain itu pada penelitian selanjutnya dengan menggunakan modul 
TKSE ini, hendaknya dilakukan dengan jumlah partisipan sedikit ( $n$-small group)

$$
\text { Psikolog praktisi, dapat }
$$

menjadikan hasil penelitian ini sebagai acuan dalam memberikan pendampingan psikologis untuk mengatasi permasalahan depresi pada wanita menikah yang mengalami infertilitas primer. Sedangkan bagi partisipan penelitian diharapkan tetap menerapkan ketrampilan yang diberikan oleh terapis. Seluruh partisipan juga diharapkan tetap membangun komunikasi positif meskipun di luar forum terapi. Hal ini dimaksudkan agar support system yang telah terbangun lewat proses terapi, dapat terus terjaga.

\section{Daftar Pustaka}

Abolghasemi, A., Farhang, S., Taherifard, M., Kiamarsi, A., \& Arabani, A. (2016). The effect of supportive expressive therapy on hope and quality of life in patients with multiple sclerosis (MS). Archives of Psychiatry and Psychotherapy, 4, 2027. doi: $10.12740 / \mathrm{APP} / 64975$

Anggraeni, M. D. (2009). Dukungan sosial yang diterima oleh perempuan yang belum berhasil dalam pengobatan infertilitas. Jurnal Keperawatan Soedirman (The Soedirman Journal of Nursing), 4(3), 94-101.

Azwar, S. (2014). Penyusunan skala psikologi. Yogyakarta: Pustaka Pelajar.

Beck, A. T., \& Alford, B. A. (2009). Depression: Causes and treatment. Philadelphia: University of Pennysylvania Press.

Berg, R. C., Landreth, G. L., \& Fall, K. A. (2006). Group counseling. New York: Routledge Taylor \& Francis Group.
Burt, V., \& Hendrick, V. (2005). Clinical manual of women's mental health. U.S.A : American Psychiatric Pub.

Cahyamita, T. (2015). Efektivitas terapi kelompok suportif ekspresif dalam menurunkan depresi pada orang dengan HIVIAIDS. (Tesis tidak dipublikasikan). Surakarta: Fakultas Psikologi Universitas Muhammadiyah Surakarta.

Chaplin, J. P. (2011). Kamus lengkap psikologi. Jakarta: PT Raja Grafindo Persada.

Connolly, M. B., Crits-Cristoph, P., Shappell, S., Barber, J. P., \& Luborsky, L. (1998). Therapist interventions in early sessions of brief supportive expressive psychotherapy for depression. The Journal of Psychotherapy Practice and Research, 7, 290-300.

Connolly, M. B., Crits-Cristoph, P., Barber, J. P., \& Luborsky, L. (2000). Transference patterns in the therapeutic relationship in supportive-expressive psychotherapy for depression. Psychotherapy Research, 10(3), 356 372. doi: $10.1093 / \mathrm{ptr} / 10.3 .356$

Crits-Christoph, P., Gibbons, M. B. C., Gallop, R., Ring-Kurtz, S., Barber, J. P., Worley, M, ... Hearon, B. (2008). Supportive expressive psychodinamic therapy for cocain dependence: A closer look. Psychoanalitic Psychology, 25(3), 483498. doi: $10.1037 / 0736-9735.25 .3 .483$

Dariyo, A. (2004). Psikologi perkembangan: Dewasa muda. Jakarta: Grasindo.

Demartoto, A. (2008). Dampak infertilitas terhadap perkawinan: Suatu perspektif gender. Laporan Penelitian Fakultas Ilmu Sosial dan Ilmu Politik (Tidak diterbitkan). Surakarta: Universitas Sebelas Maret. 
Durand, V. M. \& Barlow, D. H. (2006). Psikologi abnormal. Alih Bahasa: Linggawati Haryanto. Yogyakarta: Pustaka Pelajar.

Fobair, P., Koopman, C., DiMiceli, S., O'Hanlan, K., Butler, L. D., Classen, C. (2002). Psychosocial intervention for lesbians with primary breast cancer. Psycho-Oncology, 11(5), doi: 10.1002/ pon.624

Gishoma, D., Brackelaire, J., Munyandamutsa, N., Mujaweyazu, J., Mohand, A.A., \& Kayiteshonga, Y. (2014). Supportive expressive group therapy for people experiencing collective traumatic crisis during the genocide commemoration period in Rwanda: Impact and implications. Journal of Social and Political Psychology, 2(1), 469-488. doi: 10.5964/jspp.v2i1.292

Halgin, R. P \& Whitbourne, S. K. (2010). Psikologi abnormal (Perspektif klinis pada gangguan psikologis). Jakarta : Salemba Humanika.

Heckman, T. G., Heckman, B. D., Anderson, T., Lovejoy, T. I., Mohr, D., Sutton, M., Bianco, J. A., \& Gau, J. (2013). Supportive expressive and coping group teletherapies for hivinfected older adults: A randomized clinical trial. AIDS Behav, 17(9), 1-18. doi: 10.1007/s10461-013-0441-0

Hersen, M., \& Sledge, W. (2002). Encylopedia of psychotherapy. USA : Elsevier Science.

HIFERI (Himpunan Endokrinologi Reproduksi dan Fertilitas Indonesia). (2013). Konsensus penanganan infertilitas edisi revisi 9.1. Jakarta: HIFERI.

Karaca, A. \& Usal, G. (2015). Psychosocial problems and coping strategies among Turkish women with infertility. Korean Society of Nursing
Science, 9, 243-250. doi: 10.1016/j.anr.2015.04.007

Karren, K., Hafen, B., Smith, N., \& Frandsen, K. (2002). Mind/body health: The effects of attitudes, emotions, and relationships. San Francisco, CA: Benjamin Cummings.

Kissane, D. W., Grabsch, B., Clarke, D.M., Christie, G., Clifton, D., Gold, S ... Smith, G. C. (2004). Supportive expressive group therapy : The transformation of existential ambivalence into creative living while enchancing adherence to anticancer therapies. Psycho Oncology, 13, 755 - 768. doi: 10.1002/pon.798

Luborsky, L. (1984). Principles of psychoanalytic psychotherapy. A manual for supportive expressive treatment. USA : Basic Books, Inc.

Maslim, R. (2003). Buku saku diagnosis gangguan jiwa. Jakarta: PT Nuh Jaya.

Maldonado. (1996). Supportive expressive group therapy for people with HIV infection: A primer. California: University School of Medicine.

Mufson, L., Bufka, L., \& Wright, V. (2016). Overcoming depression: How psychologists help with depressive disorders. Diunduh dari http://www.apa.org/helpcenter/dep ression.aspx.

Nevid, J. S., Rathus, S. A. \& Greene, B. (2005). Psikologi abnormal. Edisi Kelima. Jakarta: Penerbit Erlangga.

O'Brien, M., Harris, J., King, R., \& O'Brien, T. (2008). Supportive expressive group therapy for women with metastatic-breast cancer : Improving access for Australian women through use of teleconference. Counseling and Psychotherapy Research, 8, 28-35. doi: $\underline{10.1080 / 14733140801889071}$ 
Rachmawati, D. H. (2015). Teknik relaksasi otot progresif untuk menurunkan kecemasan. (Skripsi tidak dipublikasikan). Semarang: Universitas Islam Sultan Agung.

Russell, J. D. (1974). Modular instruction : A guide to the design, selection, utilization and evaluation of modular materials. Minnesota: Burgess Publishing Company

SAMHSA (Substance Abuse and Mental Health Services Administration). (2012). Brief interventions and brief therapies for substance abuse. Rockville, MD : U. S Department of Health and Human Services.
Wahlstrom, C. M., Williams, B. K., \& Sawyer, S. C. (2006). Marriages, families, and intimate relationships: a practical introduction. USA: Pearson Education.

Watson, M \& Kissane, D. W. (2011). Handbook of psychotherapy in cancer care (first edition). UK : A John Wiley \& Sons, Ltd, Publication.

Yunitri, N. (2012). Pengaruh terapi kelompok suportif ekspresif terhadap depresi dan kemampuan mengatasi depresi pada pasien kanker. (Tesis tidak dipublikasikan). Fakultas Ilmu Keperawatan: Universitas Indonesia. 